\title{
UNA PORTADA TEQUITQUI DESCONOCIDA
}

\section{Por José Guadalupe Victoria}

Como es del conocimiento general, la influencia indígena en el arte novohispano del siglo xvr se ha discutido mucho. Todos los especialistas, en sus respectivas obras, han dedicado amplios párrafos a tratar el problema. El conjunto de portadas, pilas y cruces atriales con influencia indígena se han integrado - para su estudio- dentro de una modalidad ornamental denominada tequitqui. Dicho conjunto artístico -según están de acuerdo todos los autores-, se circunscribe al siglo xv, salvo los conocidos casos de Ixtapan de la Sal, Méx., y Tetepango, Hgo. Constituye una modalidad ornamental presente en la talla en piedra que combina intuitivamente elementos formales de diversa procedencia estilística europea, según la selección del gusto nativo. A esta manera de proceder se la puede designar como voluntad de selección formal y no creación intencional, según el parecer de Manuel González Galván; quien añade que sobre todo es una selección de aquellas formas "que le eran más afines (a los indígenas) con sus gustos e ideas preconcebidas o subyacentes". 1 Lo que da por resultado obras de carácter espontáneo en cuyo repertorio predominan motivos vegetales, humanos y animales, en ese orden de importancia. Una consideración más que podemos hacer acerca del tequitqui es su carácter rural; queremos decir con esto que no es casual que ese tipo de obras no se encuentren en ciudades. de primera importancia y categoría social. ${ }^{2}$

Por otra parte resulta interesante constatar que el número de portadas tequitqui aumenta cada día. Justo el propósito de estas líneas es dar a conocer un magnífico ejemplo de esa modalidad ornamental de la que, hasta el momento, se han desentendido los estudiosos del arte novohispano. Se trata de la portada principal de la primitiva capilla del pueblo de Tacubaya, D. F.

Sin embargo, antes de referirme a sus características formales y ornamentales, así como a su importancia dentro del conjunto de obras tequitqui, deseo apuntar algunos datos relacionados con el antiguo pueblo de Tacubaya y su convento dominico.

Los orígenes de este pueblo se remontan hasta la época prehispánica, cuando un grupo de chichimecas se estableció en el paraje denominado

1 Manuel González Galván, Arte virreinal en Michoacán.

2 Jorge Alberto Manrique, "Reflexión sobre...", p. 29. 
Coamalacatitlan; localizado más o menos donde hoy se encuentra la estación Tacubaya del Sistema de Transporte Colectivo. Esa población chichimeca dependió de Azcapozalco, aun después de que este último lugar quedó sometido al dominio político y económico de los aztecas. ${ }^{3}$

Quizá ya para estos años a Coamalacatitlan se le conocía con el nombre de Atlauhtlacoloayan, que significa "lugar donde tuerce la barranca que lleva agua", ${ }^{4}$ porque de las montañas descendian grandes arroyos; el mayor de ellos se conoció como río de Tacubaya.

Consumada la Conquista de la ciudad de Tenochtitlan por los espa. ñoles, y establecidos éstos provisionalmente en Coyoacan, Atlauhtlacoloayan quedó bajo la jurisdicción de aquella villa y tiempo después pasó a formar parte del marquesado de Hernán Cortés. Hacia mediados del siglo xvi ya se conocía a la población con el nombre de Tacubaya, que conserva hasta la fecha; misma que incluía los barrios de Xihuatecpa, Tezcácuac, Tlacateco, Huitzilan, Nonohualco, Santiago Tequisquináhuac y San Miguel Culhuacatzingo.

De acuerdo con la administración colonial, el pueblo quedó constituido en República de Indios, cuyos tributos eran entregados al gobernador del marquesado en turno, aunque parte de ellos también estaban destinados a la corona. Respecto a la administración religiosa, quienes se encargaron de evangelizar a los indios fueron los frailes dominicos que, no se sabe con certeza, iban desde la ciudad de México o tal vez desde Coyoacan a impartir la nueva religión. No fue sino hasta 1556 cuando se establecieron definitivamente y construyeron una capilla que, ya para fenecer el siglo (1591), se sustituyó por una fábrica más suntuosa, que terminaron en el primer tercio de la siguiente centuria y que incluía un monasterio de considerables proporciones.

La iglesia se puso bajo la advocación de Nuestra Señora de la Presentación, mejor conocida como La Candelaria. Tuvo categoría de parroquia, y junto con el convento fue secularizada en 1763. Los terrenos de tan vasto conjunto se extendían hasta la orilla del río, por el poniente y el sur; por el norte y occidente incluían huertas de considerable tamaño. Durante el sigĩo pasado y como consecuencia de las Leyes de Reforma, le fueron segregados cientos de metros.

La fachada principal del convento, bastante modificada, destaca por proyectarse hacia adelante respecto al paño de la iglesia; su parte

3 Antonio Fernández del Castillo, "Tacubaya", en México en el tiempo, t. 1, p. 188-194.

4 Ibidem, p. 188. 
fundamental la constituye la portería y, en el segundo piso, una capilla abierta. La portería es una estructura sencilla de planta rectangular que se abre al atrio por medio de arcos rebajados de extradós fuertemente moldurados; las columnas toscanas descansan sobre pedestales cuadrados. Es interesante este juego de arcos y columnas, pues se corresponde con otro exactamente igual que da hacia el interior.

$\mathrm{El}$ acceso principal al monasterio lo constituía la puerta de esta portería, enmarcada por la portada tequitqui que llama nuestra atención.

La constituye un arco rebajado que descansa sobre jambas, en cuyos lados hay pilastras cajeadas que proyectan sus ejes por encima de las impostas, para formar, con una moldura que los une, un alfiz. Es notable la ornamentación vegetal que cubre el extradós del arco, las jambas e impostas, asi como las bases. Entre los motivos vegetales destacan hojas de acanto y racimos de vid, pero sobre todo dos floreros en la parte superior del alfiz. Como excepcionales deben considerarse los pelícanos que aparecen en los extremos del arco.

Independientemente del repertorio formal utilizado en la decoración de esta portada, destaca el oficio conque fue realizada, pues en la mayoria de ella se percibe un cuidadoso tratamiento; sobre todo con la idea de marcar el conjunto y poner poco peso en los detalles. Lo que dio por resultado una decoración armoniosa acentuada por el ritmo de cada uno de los motivos: las hojas de acanto en el extradós del arco, los racimos de vid en las bases y las impostas, así como las hojas $y$ las flores en las jambas.

Esta pequeña portada, según nuestras observaciones, corresponde a la primitiva capilla construida en el pueblo de Tacubaya por iniciativa de los frailes dominicos, y gracias a la ayuda que prestaron los indígenas del lugar. Dicha capilla debió de ser de pequeñas dimensiones, y acaso tuvo habitaciones contiguas para el doctrinero.

Suponemos que cuando los frailes se establecieron definitivamente en Tacubaya, sus planes para construir una fábrica mayor necesariamente los haría pensar en destruir la primitiva capilla. Es casi seguro que encontraron oposición entre los indios, quienes, de alguna manera, debian sentirse orgullosos del monumento que otrora habían levantado. Así, es posible que los dos grupos -frailes e indígenas- llegaran a un acuerdo en el sentido de conservar, aunque fuera parcialmente, la antigua construcción; por eso es que la nueva iglesia se desplantó en el costado norte de la pequeña capilla y en la misma dirección que ésta, quedando incluso ambas fachadas al mismo paño. Sin embargo, como era nece- 
sario construir el convento en el lado opuesto, la fachada de aquél se proyectó más hacia adelante respecto a la fachada principal de la nueva iglesia, pues en este lugar, como en tantos otros de la Nueva España, los frailes optaron por construir siguiendo el programa arquitectónico vigente en esa época para todos los edificios monásticos, el cual -en lo que se refiere al convento- incluía la portería, a veces la capilla abierta y los claustros. En el caso que venimos estudiando la portería contó con un bellísimo acceso al convento, que no fue otro sino la portada de la primitiva capilla.

Nuestra hipótesis parece confirmarse por el hecho de que no es el único caso conocido en que, al hacer reconstrucciones o remodelaciones a las primitivas capillas, se haya optado por conservar la antigua ornamentación, sobre todo en las portadas. Al respecto conviene recordar dos casos muy significativos: Santa María Nonoalco de Mixcoac, D. F., y Santo Toribio Papalotla, Estado de México. El primero de ellos, muy cerca del monumento que nos ocupa -aunque ya en el siglo xvirI. No se destruyó la portada tequitqui cuando se modificó la estructura general de la iglesia; simplemente se reacomodaron los elementos ornamentales del barroco -muy pocos por cierto- alrededor de la antigua portada. En la portada principal de la iglesia de Papalotla ocurrió lo mismo, y eso que en otras partes del conjunto se prefirió la decoración barroca en argamasa que tanto gustó en la región. Otros ejemplos también de sumo interés son los de las portadas laterales de Texcoco, Tlalnepantla y Calimaya; los tres en el Estado de México.

En todos estos casos, pero sobre todo en los de Santa María Nonoalco y Santo Toribio Papalotla, creemos ver la veneración de los indios por las antiguas formas ornamentales creadas por sus mayores.

\section{BIBLIOGRAFIA}

1. Gonź́lez Galván, Manuel, Arte virreinal en Michoacán. México, Frente de Afirmación Hispanista (en prensa)

2. Manrique, Jorge Alberto, "Reflexión sobre el maniexismo en México", en Anales del Instituto de Investigaciones Estéticas. México, UNAM, IIE, 1971, p. 21-42.

3. México en el Tiempo, 2 vols. México, Roberto Olavarria Editor, 1946. 
DOI: http://dx.doi.org/10.22201/iie.18703062e.1978.48.1098

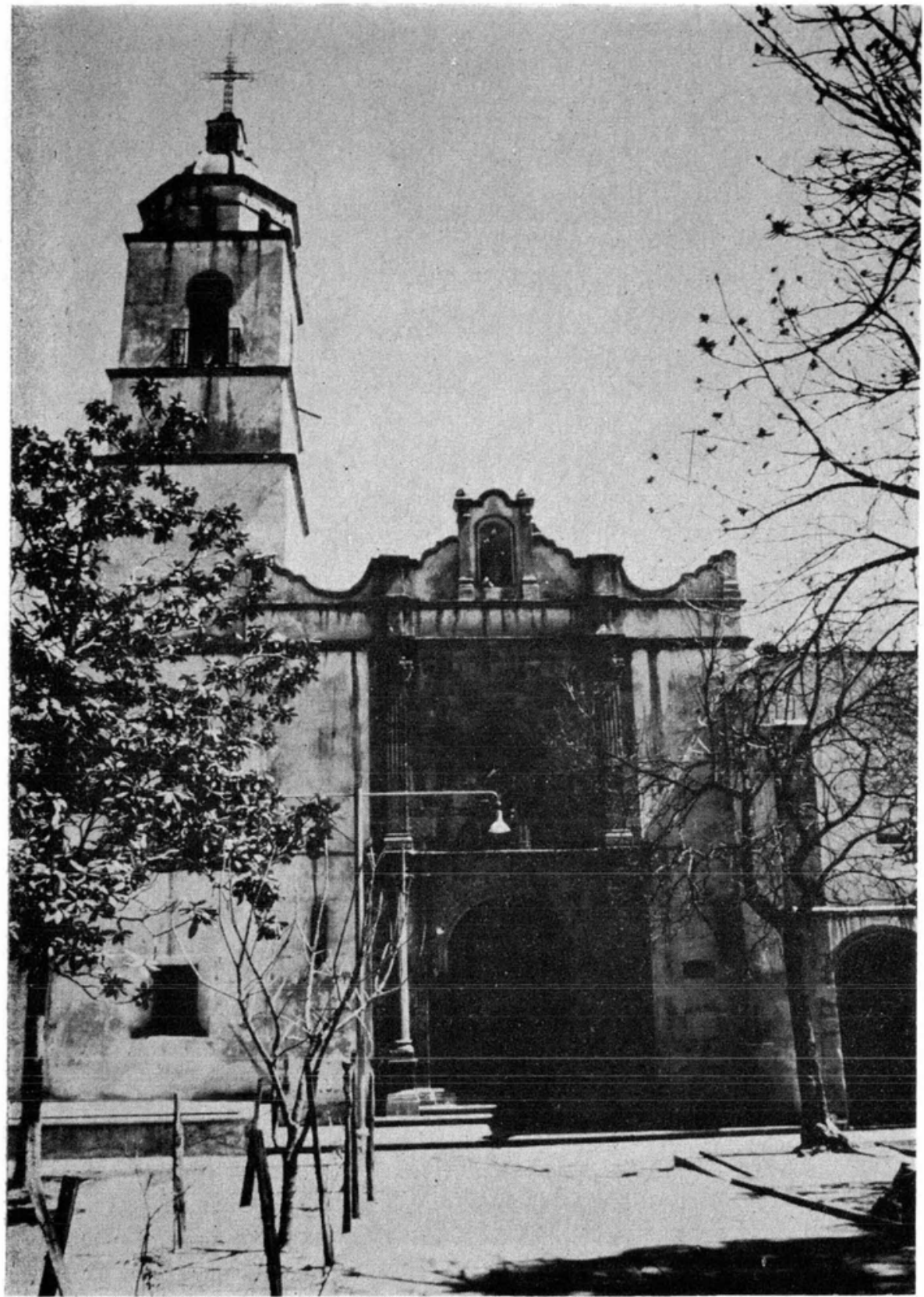

Figura 1. Vista de conjunto de la iglesia de Nuestra Señora de la Candelaria de Tacubaya, D. F. Foto J. G. V. 


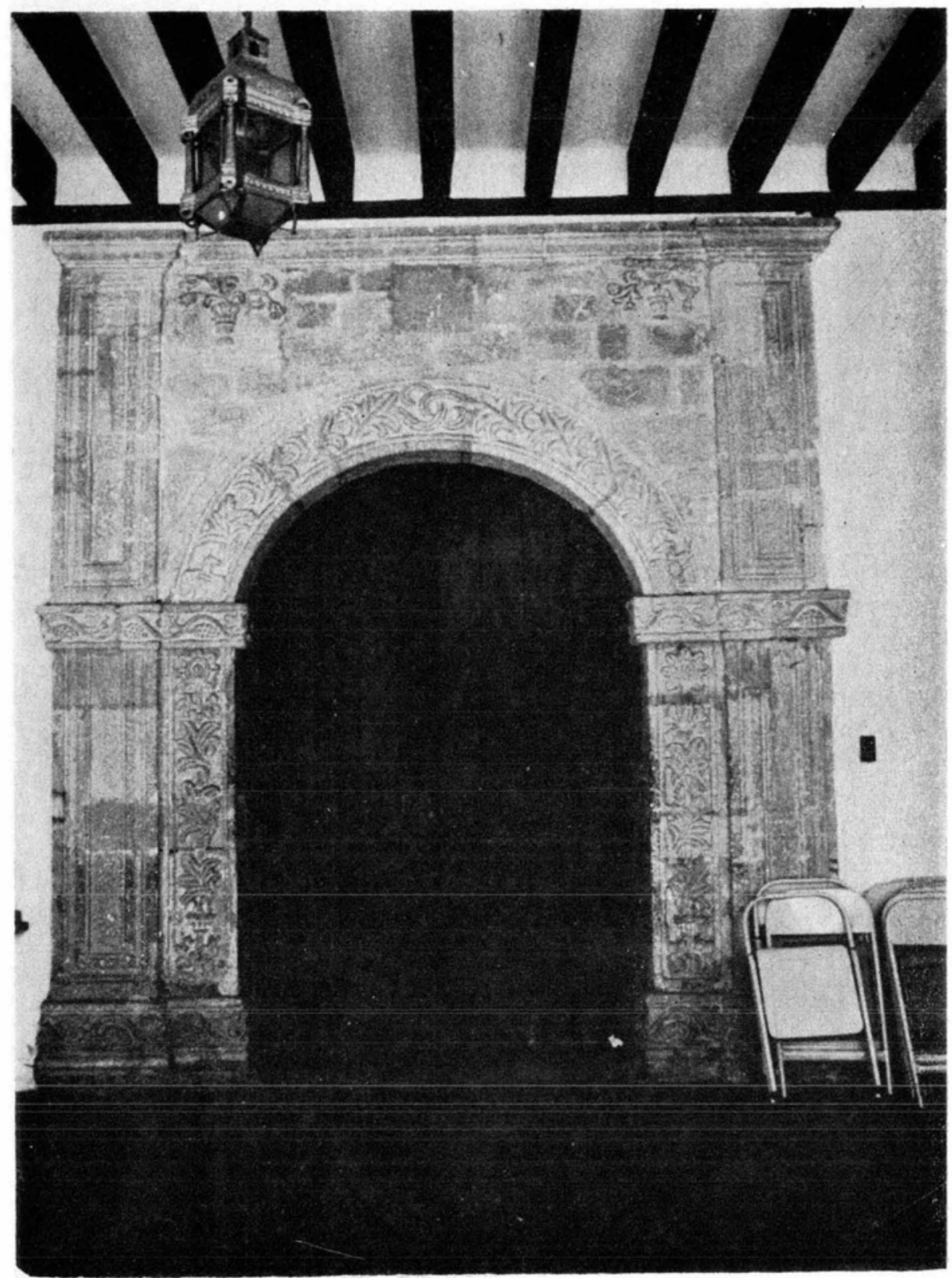

Figura 2. Portada de la primitiva capilla dominica de Tacubaya, D. F. S. XvI. Foto J. G. V. 


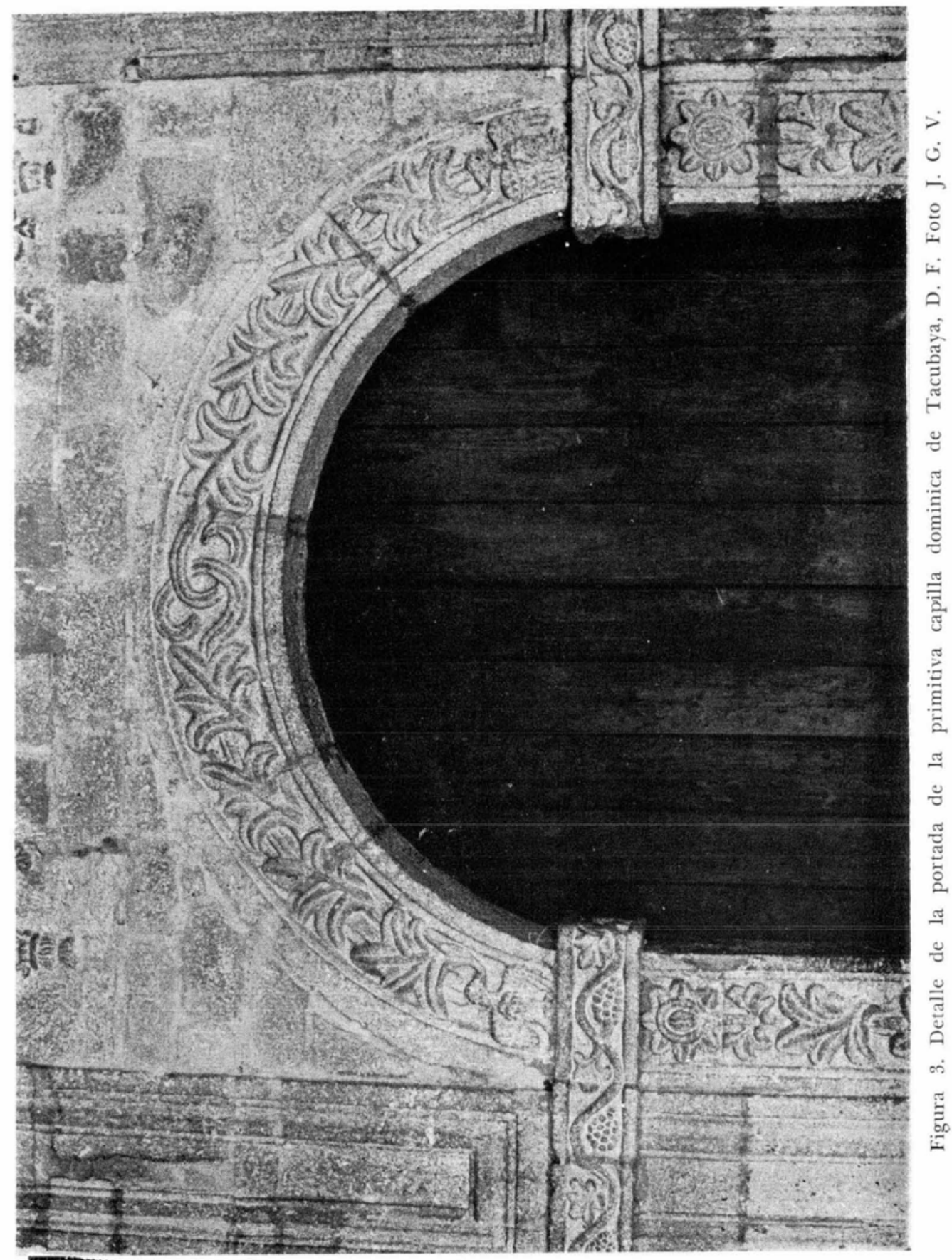


DOI: http://dx.doi.org/10.22201/iie.18703062e.1978.48.1098

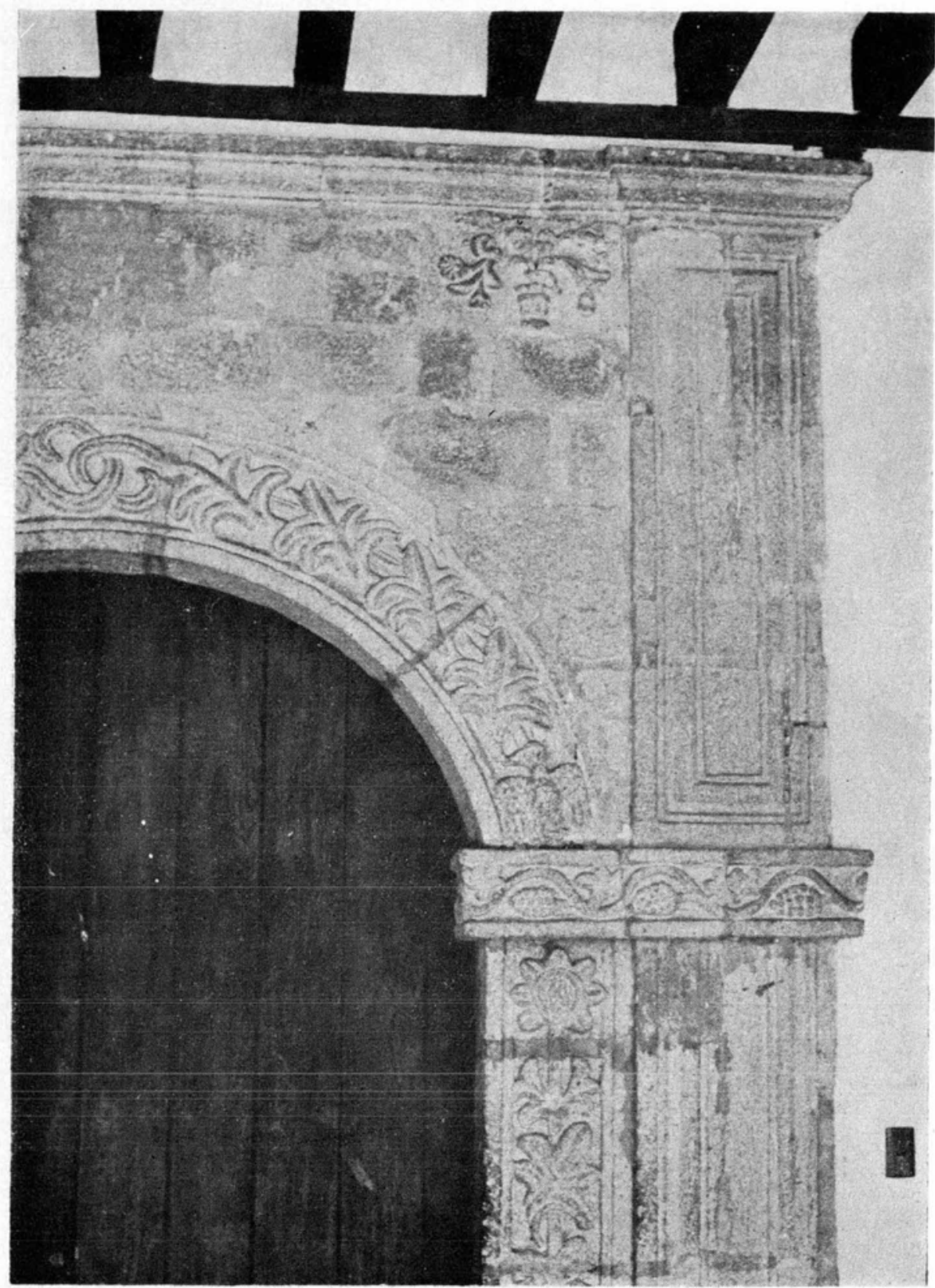

Figura 4. Detalle de la portada de la primitiva capilla dominica de Tacubaya, D. F. Foto J. G. V. 